\title{
Adaptive Web-Based Instruction for Enhancing Learning Ability
}

\author{
Wawta Techataweewan \\ Srinakharinwirot University \\ 114 Sukhumvit 23 Road, Wattana \\ Bangkok 10110, Thailand \\ walta@swu.ac.th
}

\begin{abstract}
Web technology in an instructional environment is primarily dedicated to distributing course materials to supplement traditional classroom learning. It also uses designed intelligence to adapt to learners' specific needs. The main purposes of this study were to construct and determine the efficiency of adaptive web-based instruction for LIS students. The web-based content was designed to adapt to three levels of learning ability: high, moderate and low. The system automatically collects data concerning each learner's behavior, determines the level of learning ability and provides suitable content for each learner. In addition, this web-based instruction evaluated using 80/80 standard efficiency criteria and compared the learning achievement of the students who learned through the adaptive WBI and those who learned through traditional methods. Finally, a study was conducted to evaluate students' level of satisfaction with adaptive web-based instruction. The sample consisted of 60 undergraduate students from Srinakharinwirot University, majoring in Library and Information Science. Research instruments included adaptive web-based instruction, achievement test, and satisfaction evaluation form. The findings revealed that the adaptive web-based instruction met the efficiency criteria at $80.78 / 81.17$. The learning achievement of students who learned through adaptive web-based instruction was significantly higher than those who learned through traditional methods at 0.01 level, and they were satisfied with the webbased instruction at a good level.
\end{abstract}

Keywords: Adaptive learning, Web-based instruction, Learning ability.

\section{Introduction}

The National Education Act of B.E. 2542 (1999) of Thailand in Section 22 states that, "Education shall be based on the principle that all learners are capable of learning and self-development, and are regarded as being most important; The teaching-learning process shall aim at enabling learners to develop themselves at their own pace and to the best of their potential." This policy introduced the student-centered approach into all education levels (Office of the National Education Commission, 2008). In a systematic analysis of classroom practices that spanned over a century, classroom instruction as a model ranged widely from a teacher-centered to a student-centered curriculum (Khan, 1997: 40). In the teacher-centered approach, knowledge is transmitted from 
teacher to students, the latter passively receiving information from the teacher. On the other hand, student-centered learning focuses on student's needs, abilities, interests and learning styles. The teacher facilitates learning that requires students to be active, responsible participants in their own learning and lifelong learning process. Students are responsible for setting personal, realistic goals and determining the steps toward achieving their learning objectives (Koocharoenpisal, 2005: 20-21).

The web facilitates easy distribution of knowledge and instructional resources regionally, globally or within an enterprise. The current use of the web in the instructional environment is primarily dedicated to distributing course materials to supplement traditional classrooms such as syllabus, slide presentations, assignments, calendars, notes and course readings. Additionally, teachers incorporate electronic mail and news groups to promote learning and interaction between students (Sanrach, 2002: 24). In accordance with the provision of interaction and flexibility, the web facilitates the studentcentered approach, creating a motivating and active learning environment (Zangyuan, 2010: 1). For distance education, the web is a unique tool that allows a true shift from a teacher-centered learning paradigm to an authentic student-centered learning paradigm. For students to access a variety of resources, a more flexible course design process is required that considers learners' needs and shapes instructional elements accordingly.

\section{Adaptive Web-Based Instruction}

Web-based instruction (WBI) can be viewed as an innovative approach for delivering instruction to a remote audience. Instruction involves the delivery of information and activities that facilitate learners' attainment of specific learning goals (Smith et al, 1993: 2). Early WBI offered the same course content using the same didactic presentation method to all students. With growing data, number and diversity of users, the complexity of human-computer interaction continually increases. Increasingly, modern software adapts to users, for example, programs that automatically adapt themselves to unacquainted or inexperienced users (Chen et al, 2005: 104). Recent adaptive learning systems take into account user preferences, skills and interests to enhance knowledge acquisition in a personalized computer-supported teaching environment. To behave adaptively, WBI must be able to recognize a learner's needs or preferences and generate a concept of each learner. Adaptive web-based instruction builds an internal model of an individual learner and modifies instruction accordingly. Adaptive WBI has been defined in many different ways, which are closely related to two aspects of its adaptive systems as follows:

2.1 Adaptive presentation means to adapt the content of a page accessed by learners to current knowledge depending on their learning characteristics. This is similar to a teacher who typically adapts teaching content for each individual student based on their unique needs. Existing adaptive presentation technologies deal with text adaptation that adjusts for different learners at different times who may receive different content even when on the same page. Adaptive presentation also provides the same page to meet the needs of every student.

2.2 Adaptive navigation means to support students with hyperspace orientation and navigation by changing the appearance of visible links. Adaptive navigation can be 
considered a generalization of curriculum sequencing technology in the hypermedia context with the same goal of helping students find the optimal path to learning materials. Curriculum sequencing means to organize instructional units or curriculum elements into a hierarchy of related courses, models, lessons and presentations. Each instructional unit typically has an objective (Chen et al, 2006: 379). Three techniques of adaptive navigation include adaptive guiding, adaptive link annotation and adaptive link hiding (Sanrach, 2002: 25-26).

The most well-known adaptive learning systems are AHA, InterBook, and APels (Sluijs, et al. 2009: 46). AHA is an open source adaptive hypermedia system mainly used in the education domain. It supports several adaptation techniques such as adaptive guiding, link annotation and adaptive link hiding (De Bra et al, 2006: 133). InterBook affords an environment for authoring and providing adaptive online textbooks. It supports adaptive navigation that guides users' hyperspace exploration using annotation (Brusilovsky, 1998: 293). APelS or Adaptive Personalized eLearning Service is a multi-model, meta-data driven adaptive hypermedia system that separates the narrative, content and learner into different models. The adaptive engine in APelS is a rule-based engine that produces a model for personalized courses based on a narrative and the learner model (Conlan, 2002: 100). Currently, most adaptive learning systems consider learners' preferences and interests for developing individualized service. However, some systems neglect the importance of learner ability when implementing personalized mechanisms. Likewise, some researchers emphasize that personalization should consider levels of learner knowledge, especially in relation to learning (Papanikolaou et al, 2002: 338-339). In summary, effective consideration of learner ability can improve individual learning performance and achievement of learning goals.

\section{System Design and Components}

The system was designed for the adaptation of course content to recognize and appreciate students' learning ability. Students' learning ability level is approached through the use of various learning "agents." The agents are employed to adapt the presentation of course content for each learning unit according to the ability of the learner, as determined by each formative assessment test. The system components include learning interface agent, feedback agent, courseware provision agent and courseware management agent as shown in figure 1 .

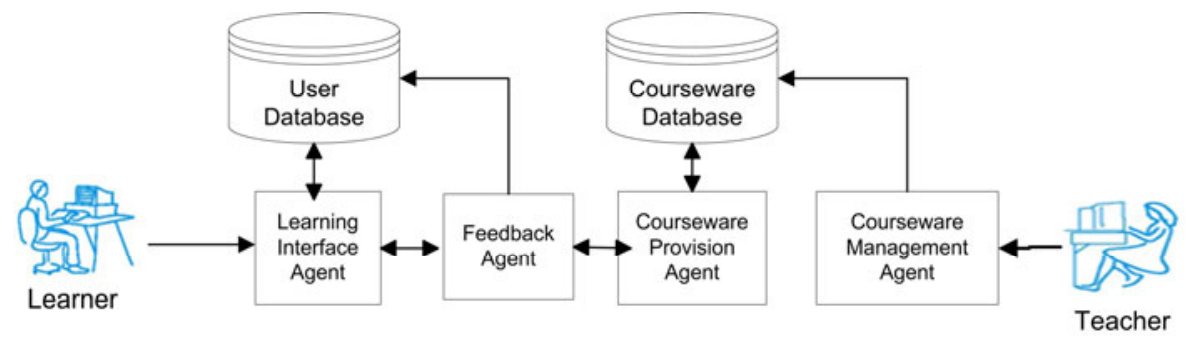

Fig. 1. Adaptive WBI architecture and components 
The learning interface agent provides a friendly user interface to interact with learners by checking their accounts in the user database. If the learner has already registered, the system retrieves their individual learning profile. The agent also conveys the learner's feedback to the feedback agent, and receives results from the system adaptive engines to display appropriate course content to the learner.

The feedback agent obtains learner information from the learning interface agent of the user database and passes the formative assessment scores of each learning unit to the courseware provision agent for evaluating that learner's ability and providing appropriate course content. Meanwhile, the feedback agent sends information concerning a user's learning status to the user database for updating the learner's profile.

The courseware provision agent collects a learner's scores from the feedback agent to evaluate their ability with criteria such as, 8-10 = high level, 5-7 = moderate level and 3-4 = low level. If the scores lower than 3, the learner has to repeat the past learning unit. The courseware provision agent then retrieves the course content and matches it to the learner's ability from the courseware database.

The course management agent helps teachers manage the course on the web. They access the system to upload, delete or revise the courseware database, which is maintained by the courseware management agent. A teacher can design course content and configure specific criteria based on students' various levels of learning ability.

Using the adaptive presentation approach in an adaptive learning system, the course content in this research was designed for high, moderate and low levels of learning ability. Specifically, the course content was divided into three different amounts of lessons per unit for each of the three levels.

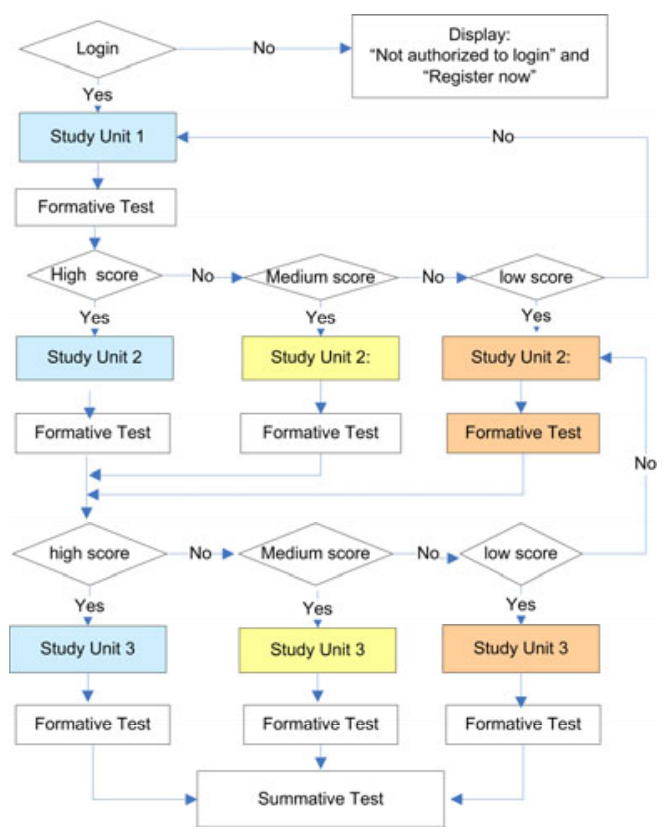

Fig. 2. Adaptive WBI work flow 
While studying, students in the experimental group could shift to a higher or lower level depending on their formative assessment scores until they finished the course, as diagrammed in figure 2 .

Actually, most LIS students felt that the Dewey Decimal Classification System (DDC) course was difficult for them because there was a lot of content and memorization. Therefore, the web-based screen design was concerned with motivation through a balance of graphics and text, plus animation games for practice, as shown in figures 3 .

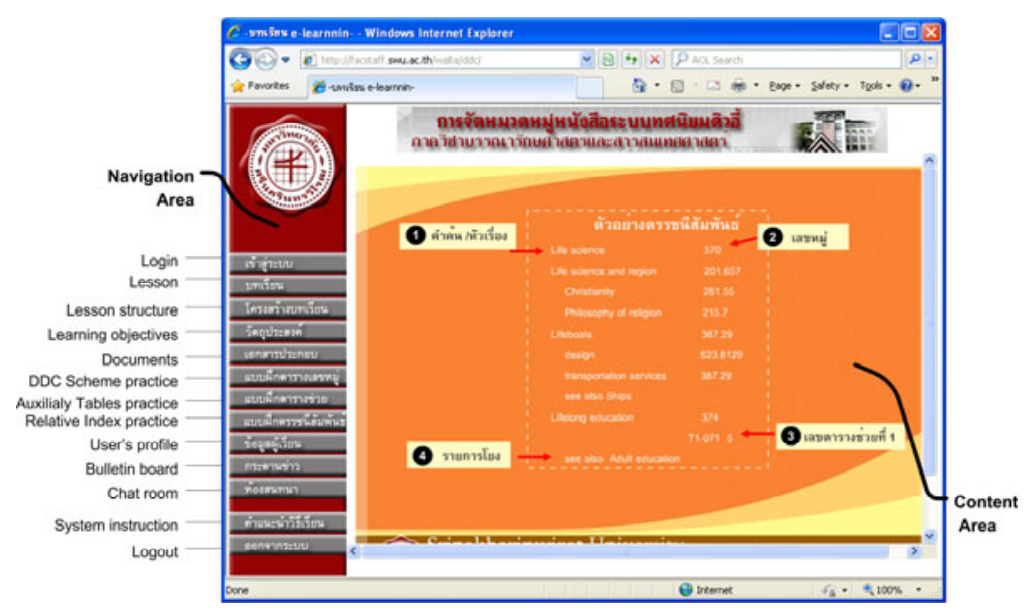

Fig. 3. Learning webpage design

\section{Research Questions and Objectives}

The purpose of this research was to develop adaptive web-based instruction on the Dewey Decimal Classification System, which is a compulsory course for Library and Information Science students. Course content was designed to adapt to high, moderate and low levels of learning ability. The system automatically collected data on each student's behavior, determined their level of learning ability, and provided suitable lessons for them. This researched addressed the following questions.

1. How can adaptive WBI be designed to appreciate student's learning ability?

2. How does the outcome from adaptive WBI compare to traditional classroom learning?

3. To what degree are students satisfied with adaptive WBI?

The objectives of this study were:

1. To develop adaptive WBI for students according to their individual learning ability.

2. To elucidate differences between learning achievement in traditional classrooms and adaptive WBI.

3. To analyze students' level of satisfaction with adaptive WBI. 


\section{Research Methodology}

The study employed an experimental research methodology using pre-test, post-test control group design. The research instruments included adaptive WBI, the learning achievement test and the system satisfaction evaluation form. An experiment was conducted to investigate the system's educational effectiveness. The study included 60 Library and Information Science students at Srinakharinwirot University who had not previously taken the Dewey decimal classification course. The students were purposely distributed into two equal groups: the control group consisted of third-year students who were enrolled in a conventional learning environment while the experimental group consisted of second-year students who were placed in an adaptive web-based learning environment. Both groups took the pre-test before the course and post-test after completing it. The efficiency criteria of the system was E1/E2 $=80 / 80$, that compared the percentage of formative assessment scores with the summative assessment scores.

\section{Research Results}

The means and standard deviations of data for the pre-test, post-test and formative tests were analyzed using a t-test, yielding quantitative results. This study aimed to address the research problems as follows:

6.1 Adaptive WBI was designed to appreciate students' learning ability through learning content design and the adaptive engine of the system. The learning ability levels of the learners were evaluated at high, moderate and low levels depending on the formative test scores from each learning unit. The system then determined the course content to match their level. Therefore, the students study the same course content but different amount of content in each unit depending on their learning ability. The outcome for adaptive WBI compared to the traditional classroom indicated that adaptive WBI met the efficiency criteria at 80.78/81.17, as shown in table 1 . There were 30 questions on the three formative tests and 20 questions on one summary test with adaptive WBI.

Table 1. Efficiency of adaptive WBI as criteria of E1/E2

\begin{tabular}{lccc}
\hline \multicolumn{1}{c}{ Assessment } & Scores & $\bar{X}$ & Percentage \\
\hline Formative tests (E1) & 727 & 24.23 & 80.78 \\
Summary test (E2) & 487 & 16.23 & 81.17 \\
\hline \hline
\end{tabular}

6.2 Differences between learning achievement in the traditional classroom and adaptive WBI were examined by comparing the pre-test and post-test scores. Different scores between the experimental and control groups were used as an index of learning achievement. The first set of data in table 2 shows a significant difference at .01 between the achievements of the two groups, indicating that learners benefited more from the adaptive learning environment. 
Table 2. Comparison of learning outcome between experimental and control groups

\begin{tabular}{llclc}
\hline \multicolumn{1}{c}{ Students } & $\mathrm{N}$ & $\bar{X}$ & S.D. & t-test \\
\hline Experimental group & 30 & 16.23 & 1.25 & $3.248^{* *}$ \\
Control group & 30 & 14.73 & 2.10 & \\
\hline \hline
\end{tabular}

** Significant at $P<.01$.

6.3 All 30 students in the experimental group who used adaptive WBI responded to the satisfaction questionnaire after finishing the course. The satisfaction evaluation form was analyzed using the Likert method, with a scale consisting of the elements: 5 = Very Good, 4 = Good, $3=$ Fair, 2 = Less and $1=$ Unsatisfied, respectively. Results from the evaluation showed that students were overall satisfied with studying with adaptive WBI at a good level. Specific evaluation topics such as web design, learning facilities and course content also yielded good levels of satisfaction (as shown in table 3). Many students' opinions indicated that they preferred learning on the web, such as, "It isn't difficult to build the DDC number." "It's cool;" "I love the games. It makes me easily memorize the DDC scheme;" "Not boring to study on the web." and so on.

Table 3. Satisfaction evaluation of adaptive WBI

\begin{tabular}{|c|c|c|c|}
\hline Evaluation lists & $\overline{\bar{X}}$ & S.D. & Meaning \\
\hline \multicolumn{4}{|l|}{ 1. Webpage design } \\
\hline 1.1 Menu sequencing & 4.37 & & Good \\
\hline 1.2 Menu positioning & 4.57 & & Excellent \\
\hline 1.3 Attractive design & 4.57 & & Excellent \\
\hline 1.4 Font formatting & 4.53 & & Excellent \\
\hline 1.5 Font sizes & 4.50 & & Excellent \\
\hline 1.6 Font colors & 4.53 & & Excellent \\
\hline 1.7 Graphics & 4.13 & & Good \\
\hline 1.8 Overall web design & 4.43 & & Good \\
\hline Total & 4.45 & 0.15 & Good \\
\hline \multicolumn{4}{|l|}{ 2. Learning management system } \\
\hline 2.1 User friendly & 4.40 & & Good \\
\hline 2.2 Interactive styles & 4.10 & & Good \\
\hline 2.3 Guidance and feedback & 4.30 & & Good \\
\hline 2.4 Full required functions & 4.13 & & Good \\
\hline 2.5 Overall LMS & 4.20 & & Good \\
\hline Total & 4.23 & 0.12 & Good \\
\hline \multicolumn{4}{|l|}{ 3.Course content } \\
\hline 3.1 Amount of content & 4.27 & & Good \\
\hline 3.2 Content sequencing & 4.30 & & Good \\
\hline 3.3 Understandable content & 4.27 & & Good \\
\hline 3.4 Suitable content & 4.33 & & Good \\
\hline 3.5 Interesting content & 4.10 & & Good \\
\hline 3.6 Presentation & 4.43 & & Good \\
\hline 3.7 Examples & 4.33 & & Good \\
\hline Total & 4.29 & 0.10 & Good \\
\hline Total & 4.32 & 0.12 & Good \\
\hline
\end{tabular}




\section{Discussion}

Adaptive WBI is a more powerful teaching method to support the student-centered learning approach. The program was designed to assign a suitable amount of course content for each student's learning ability regarding their concentration and memorization. Additionally, the DDC scheme also offered practice with animation games, a chat room, bulletin board and course documents that motivated students and helped them remember the material. For examples, games may promote further the students' weakening of attention and concentration is an internal power of their mind, or controlled by external elements such as computer which totally depends on the person's own. The experimental students using WBI improved their learning retention and earned higher scores than the control students. Furthermore, students participating in the DDC course completed the lessons more quickly than those in the conventional classroom. The main reasons for this remarkable difference were the availability of computers and the freedom of learning. Consequently, a lot of students finished the course within a very brief period of time.

\section{Conclusions and Future Works}

Adaptive WBI aims to formulate an environment that supports students to optimize their individual learning ability. The proposed adaptive WBI for enhancing learning ability provides learning content that can be adapted to the various abilities of students. Meanwhile, this approach can be integrated for all courseware while developing individual learning ability. Experimental results indicated that WBI can successfully recommend appropriate course materials to students based on individual ability and help them learn more effectively in a web-based learning environment. In general, web-based instruction meets the needs of students. In this study, the system supports only the adaption of the learning content to each student. Adaptive WBI proposes an adaptive presentation approach to reveal students' learning needs. Further study should aim to more identify the personal needs and learning styles. Therefore, teachers can set several requirements about a course to response the students' needs and styles. Likewise, the adaptive WBI should compare not only classroom, but also the simple web-based learning environment.

\section{References}

Brusilovsky, P., Eklund, J., Schwarz, E.W.: Web-based education for all: A tool for development adaptive courseware. Computer Networks and ISDN Systems 3(1-77), 291-300 (1998)

Brusilovsky, P., Schwarz, E., Weber, G.: ELM-ART: An intelligent tutoring system on World Wide Web. In: Lesgold, A.M., Frasson, C., Gauthier, G. (eds.) ITS 1996. LNCS, vol. 1086, pp. 261-269. Springer, Heidelberg (1996)

Chen, C., Liu, C., Chang, M.: Personalized curriculum sequencing utilizing modified item response theory for web-based instruction. Expert Systems with Applications 30, 378-396 (2006) 
Chen, S.Y., Magoulas, G.D.: Adaptive and adaptive hypermedia systems. In: Universal Access in the Information Society. IRM, Hershey (2005)

Conlan, O., Wade, V.P., Bruen, C., Gargan, M.: Multi-model, metadata driven approach to adaptive hypermedia services for personalized elearning. In: De Bra, P., Brusilovsky, P., Conejo, R. (eds.) AH 2002. LNCS, vol. 2347, pp. 100-111. Springer, Heidelberg (2002)

De Bra, P., Smiths, D., HÖver, K.M.: The design of AHA! In: Proceedings of the 17th ACM Conference on Hypertext and Hypermedia: Hypertext 2006, Odense, Denmark, pp. 133-134 (December 2006)

Khan, B.H. (ed.): Web-based instruction. Educational Technology, Englewood Chiffs (1997)

Koocharoenpisal, N.: A development of learner-centered Science curriculum on "Chemicals in daily Life" for lower secondary students, Dissertation, Ed.D. (Science Education), Bangkok: Srinakharinwirot University (2005)

Papanikolaou, K.A., Grigoriadou, M., Magoulas, G.D., Kornilakis, H.: Towards new forms of knowledge communication: the adaptive dimension of a web-based learning environment. Computers \& Education 39, 333-360 (2002)

Office of the National Education Commission, International Relations and Cooperation Center for Educational Reform, National Education Act of B.E. 2542 (1999), http: / /www.moe.go.th/English/edu-act.htm (retrieved April 17, 2008)

Sanrach, C.: Adaptive and intelligent web-based learning environment. Journal of Academic Computer Education 1(1), 24-45 (2002)

Sluijs, K., Höver, K.M.: Integrating adaptive functionality in LMS (2009) http://online-journals.org/i-jet/article/view/958 (retrieved December 10, 2009)

Smith, P.L., Ragan, T.J.: Instructional design. Macmillan, New York (1993)

Zangyuan, O.: The Application of an adaptive, web-based learning environment on Oxidationreduction Reactions. International Journal of Science and Mathematics 8(1), 1-23 (2010) 